\title{
A RESTAURAÇÃO DA IMAGEM ENTRE ANÁLISE DO DISCURSO E CIÊNCIAS DA COMUNICAÇÃO: O CASO DA ENTREVISTA TELEVISIONADA DE LILIANE BETTENCOURT
}

\section{Keren Sadoun-Kerber ${ }^{i}$}

Resumo: $O$ objetivo deste artigo é ver a maneira pela qual se aplica o quadro teórico da restauração de imagem no caso preciso e restrito de uma entrevista. Para fazer isso, apresentamos, num primeiro momento, teorias que permitem a análise da restauração de imagem em uma situação de interação. Em seguida, à luz desse modelo, tratamos do caso em estudo - a reparação de imagem de Liliane Bettencourt, herdeira da L'Oréal, na primeira entrevista televisionada que se segue ao escândalo do «caso Bettencourt».

Palavras-chave: Ato ameaçador da face. Ethos. Interação. Restauração de imagem.

Abstract: This article aims at verifying how the theoretical framework of image restoration applies to the specific and limited case of an interview. We will first present theories that support the analysis of image restoration in a situation of interaction. Then, drawing upon this model, we will analyse a case study: the image reparation of Liliane Bettencout, the heir of L'Oréal, in the first TV interview following the scandal of the "Bettencourt affair".

Keywords: Face threatening act. Ethos. Interaction. Image restoration. 
EID\&A - Revista Eletrônica de Estudos Integrados em Discurso e Argumentação, Ilhéus, n. esp. ADARR, mai.2016.

\section{Introdução}

O objetivo deste artigo é observar a maneira com a qual se aplica o quadro teórico da restauração de imagem no caso preciso e restrito de uma entrevista. Para fazer isso, nós vamos inicialmente apresentar teorias que abordam a questão da reparação da imagem, considerando o fato de que ela deve aqui ser analisada na situação de interação que caracteriza o corpus. Em seguida, à luz desse modelo, nós trataremos do caso selecionado para este estudo - a reparação da imagem de Liliane Bettencourt, na primeira entrevista televisionada que se segue ao escândalo do "caso Bettencourt".

A restauração da imagem, enquanto processo, está estreitamente ligada ao retrabalho do ethos (AMOSSY, 2010). Com efeito, ambos estão ligados à maneira pela qual um indivíduo busca modelar sua imagem de si em seu discurso para melhor agir sobre seu auditório. No entanto, o segundo é um processo global que pode ser realizado para modificar sua imagem segundo as necessidades do momento, enquanto o primeiro busca mais especificamente reparar os estragos causados a sua imagem pública. O retrabalho da imagem mobiliza ao mesmo tempo modelos culturais (estereótipos e representações compartilhadas) e modalidades discursivas que estão ancoradas em gêneros específicos; ele pode mobilizar meios extremamente diversos. O processo de restauração de imagem se faz segundo estratégias globais que diversos pesquisadores tentaram repertoriar.

Inspirando-se em trabalhos anteriores efetuados sobre vários aspectos da restauração de imagem (GOFFMAN, 1967; WARE e LINKUGEL, 1973; BURKE, 1969), William Benoît (1995) propõe cinco grandes estratégias para essa empreitada. A primeira estratégia mencionada é a da denegação, que consiste em negar, seja o fato de que o ato é prejudicial, seja que a pessoa o tenha cometido. Para a segunda possibilidade, a pessoa pode deslocar a responsabilidade relançando-a sobre um outro, isto é, encontrar um bode expiatório para o qual é possível transferir a culpa. Essa estratégia é também conhecida sob seu nome inglês "victimage" proposto por Kenneth Burke (1969), que, segundo ele, é uma das vias para reduzir a culpabilidade sentida.

A segunda estratégia é a redução da responsabilidade pelo ato cometido, que pode se manifestar segundo quatro subcategorias. O ato condenado é apresentado como uma reação a uma provocação, de modo que a pessoa não seria totalmente responsável por ele. Uma segunda variante consiste na falta de informações de que dispunha o indivíduo concernido. Uma terceira 
EID\&A - Revista Eletrônica de Estudos Integrados em Discurso e Argumentação, Ilhéus, n. esp. ADARR, mai.2016.

variante consiste em dizer que se trata de um acidente. A quarta alega que se trata de boas intenções que foram malsucedidas.

A terceira estratégia consiste na redução do sentimento de ofensa produzido pelo ato cometido, que pode se manifestar segundo algumas subestratégias: a primeira é o reforço das qualidades positivas da pessoa culpada - tática que é mais eficaz quando ela se faz em relação direta com o ato condenado. A segunda subestratégia é a minimização da ofensa. Ela consiste em dizer ou em mostrar que o ato é menos grave do que se podia imaginar. A terceira é a diferenciação de um ato em relação a outro mais grave. A quarta é a transcendência do ato que se comete, incluindo-o em um contexto mais vasto; em geral, essa estratégia acentuará os valores elevados que guiaram a pessoa em questão. Em seguida, encontramos o ataque ao adversário: trata-se de desacreditar a pessoa do acusador para reduzir sua credibilidade. A sexta variante é a da compensação proposta para reduzir os sentimentos de hostilidade em relação à pessoa culpada.

A quarta estratégia é a ação de correção, que consiste em prometer que as coisas não se repetirão mais, ou em endireitar a situação, se possível. A quinta estratégia consiste em um pedido de desculpas e a expressão de arrependimento: é a "mortificação".

Se essas categorias podem ser úteis para situar estratégias globais, esse enfoque não proporciona, entretanto, os instrumentos linguísticos ou argumentativos que permitiriam uma análise aprofundada suscetível de apreender a complexidade dos discursos. Para fazer isso, empregaremos instrumentos tomados de empréstimo da linguística - a pragma-semântica de Ducrot (1991), mas, sobretudo, a análise do discurso em sua relação com as teorias da argumentação (PERELMAN e OLBRECHTS-TYTECA, 2008 [1958]; AMOSSY, 2000, 2010) assim como a análise interacional (KERBRATORECCHIONI, 2010 [1990]) indispensável para o estudo de uma entrevista. Veremos na análise da entrevista televisionada de Bettencourt como as categorias das ciências da comunicação são complementadas pelos instrumentos fornecidos pelas ciências da linguagem, sem os quais é impossível: efetuar uma análise dos procedimentos por meio dos quais a pessoa atacada tenta reparar sua imagem pública danificada, bem como enxergar como se concretizam as estratégias enumeradas por Benoît. 
EID\&A - Revista Eletrônica de Estudos Integrados em Discurso e Argumentação, Ilhéus, n. esp. ADARR, mai.2016.

\section{O processo de restauração da imagem no gênero entrevista}

O que complica a análise é a situação de interação em que a pessoa que se dedica a empreender a reparação da imagem é confrontada a atos ameaçadores para sua face (GOFFMAN, 1967) $)^{1}$. Ora, quando a face ${ }^{2}$ sofre uma ameaça, "é preciso realizar a preservação da fachada [face]" (GOFFMAN, 2012 [1967], p. 34, colchetes do tradutor), um trabalho de "figuração", segundo a tradução de Kerbrat-Orecchioni (2010 [1990], p. 122), deve se efetuar. Na esteira de Goffman, estão Brown e Levinson (1987 [1978]) que desenvolvem a noção de atos ameaçadores para a face (Face threatening acts ou FTA), repertoriando diferentes tipos de ameaças (on record e off-record), assim como as estratégias de polidez utilizadas para evitar ameaças ou para recuperar a face perdida. Podemos também utilizar o termo desafio, proposto por Weizman (2006, seguindo LABOV e FANSHAL, 1977, p. 97), para designar "cada ação - verbal ou não - que indica (explicitamente) ou sugere (implicitamente) que seu destinatário não é competente em seu papel” (WEIZMAN, 2008, p. 138). A interação no caso de estudo escolhido se desenvolve numa entrevista de informação, que é um gênero conflitual por essência e onde cada interlocutor deve se posicionar (Ibidem). Os desafios podem ser relativos seja ao papel interacional dos participantes (entrevistador/entrevistado) seja a seu papel social (jornalista/mulher de negócios).

A entrevista de informação é um subgênero específico na categoria das entrevistas. Suas características próprias são a mídia (suporte de comunicação de massa, aqui a televisão); os participantes são tomados numa estrutura diádica de pergunta-resposta, tendo cada um seu papel na interação (GOFFMAN, 1967; WEIZMAN, 2008); os temas abordados giram, em geral, em

\footnotetext{
1 NT: As referências da obra de Goffman (1967) seguem a tradução ao Português Brasileiro, realizada por Fábio Rodrigues Ribeiro da Silva e publicada pela Editora Vozes em 2012. Nesta tradução, o termo face é traduzido por fachada, apesar de não ser o termo corrente na academia.

2 Goffman (1967) utiliza a face como uma noção sinônima de imagem de si, colocando o acento sobre os códigos sociais de comportamento: "the positive social value a person effectively claims for himself by the line others assume he has taken during a particular contact. Face is an image of self delineated in terms of approved social attributes - albeit an image that others may share, as when a person makes a good showing for his profession or religion by making a good showing for himself"

"o valor social positivo que uma pessoa efetivamente reivindica para si mesma através da linha que os outros pressupõem que ela assumiu durante um contato. A fachada [face] é uma imagem do eu delineada em termos de atributos sociais aprovados - mesmo que essa imagem possa ser compartilhada, como ocorre quando uma pessoa faz uma boa demonstração de sua profissão ou religião ao fazer uma boa demonstração de si mesma" (GOFFMAN, 2012 [1967], p. 13-14).
} 
EID\&A - Revista Eletrônica de Estudos Integrados em Discurso e Argumentação, Ilhéus, n. esp. ADARR, mai.2016.

torno de um tema da atualidade de alcance geral; a duração da entrevista é relativamente curta, aproximadamente dez minutos (JUCKER, 1986).

Para este artigo, nós escolhemos um caso específico como corpus: a primeira entrevista televisionada que se seguiu ao estouro do escândalo chamado "caso Bettencourt". Este começa como um conflito familiar, mas se revela rapidamente tentacular por seus desdobramentos e a implicação de políticos (ARFI e LHOMME, 2010). O caso é designado pelo nome de família de Liliane Bettencourt - Liliane (Henriette Charlotte Schuller) Bettencourt, mulher de negócios francesa, é a mulher mais rica da França e do mundo ${ }^{3}$. Ela é herdeira da L'Oréal ${ }^{4}$ e foi sua principal acionária até 2012.

A entrevista ocorre em um canal central, TF1, numa hora de grande audiência. $\mathrm{O}$ aspecto grande público é importante, pois nosso interesse está voltado para a imagem da pessoa na esfera pública e não em ambientes particulares de negócios.

Devido a limitações de espaço, nós escolhemos dois temas centrais que constituem reprimendas dirigidas à bilionária. O primeiro tema é da ordem do privado e diz respeito a um conflito entre Liliane Bettencourt e sua filha, Françoise Meyers-Bettencourt, devido à relação que se desenvolveu entre Liliane e um fotógrafo da alta sociedade, Jean-Marie Banier. Beneficiário de uma doação que se eleva a um bilhão de euros, este é suspeito por Françoise de ter se aproveitado de sua mãe, tirando vantagem de sua idade avançada e de seu estado mental. Esse conflito, denominado nos meios de comunicação "eixo familiar", motivou gravações clandestinas das conversas de Liliane Bettencourt em seu domicílio, que revelaram mais tarde o verdadeiro escândalo designado pelo nome "caso Bettencourt", relativo desta vez a uma evasão fiscal (tratada aqui) e à corrupção dos políticos (que não será abordada aqui por limitações de espaço). A evasão fiscal diz respeito ao partido político majoritário no governo da época (UMP), o presidente em

3 Segundo "Complément d'enquête", programa veiculado pelo canal France 2, dia 31/10/2013.

4 A empresa L'Oréal é em si um assunto que preenche livros. À parte seu sucesso (COLLIN, Béatrice et ROUACH Daniel. Le modèle L'Oréal: les stratégies clés d'une multinationale française, Editions Pearson, 2009), sua história é, além disso, entrelaçada com a história da França durante seus momentos menos gloriosos: o fundador, Eugène Schueller, pai de Liliane Bettencourt, tinha laços fortes com a extrema direita (ABESCAT BRUNO). La saga de Bettencourt: L'Oréal, une fortune française, Paris, Plon, 2002). Ele também financiou a Cagoule. Segundo Bar Zohar (Bitter scent. The case of L'Oréal, Nazis, and the Arab boycott. New York. N.Y.: E.P. Duttan, 1996), a L'Oréal se apropriou de um prédio pertencente a judeus para fazer dele sua sede. A questão dos apartamentos e imóveis confiscados dos judeus durante o período de Vichy constitui assim uma acusação que implica também a multinacional. Uma das histórias de espoliação prosseguidas na justiça é a de Monica Waitzfelder, 2004, L'Oréal a pris ma maison. Les secrets d'une spoliation. Paris, Hachette. 
EID\&A - Revista Eletrônica de Estudos Integrados em Discurso e Argumentação, Ilhéus, n. esp. ADARR, mai.2016.

exercício Nicolas Sarkozy e seus ministros, sobretudo o ministro do orçamento, Woerth, cuja mulher trabalha para a bilionária como diretora de investimentos.

Tecnicamente, o estabelecimento do corpus para análise consiste numa transcrição da entrevista, a numeração dos turnos de fala e seu recorte segundo os temas unificadores.

O procedimento da análise será o seguinte: inicialmente tratamos das questões da entrevistadora, a saber, a formulação, a forma como se dirige à entrevistada, o lançamento de um desafio ou um ato ameaçador para a face da entrevistada, o tipo de desafio, o tom, as palavras escolhidas, a maneira pela qual a entrevistadora preserva seu ethos, a eventual preservação de face de sua entrevistada (GOFFMAN, 1967; BROWN e LEVINSON, 1978). Nós buscamos igualmente saber qual papel social da entrevistada é posto em primeiro plano por sua entrevistadora se esta insiste sobre certos assuntos e como ela o faz (repetição, reformulação, etc.). Em um segundo momento, examinamos a relação entre as perguntas e as respostas. A reação da entrevistada a cada questão posta é estudada em sua dimensão estratégica, argumentativa e discursiva - sendo essencial estudar a maneira pela qual a pessoa reage face às questões que contêm desafios potenciais e acusações que levaram à degradação de sua imagem pública. $O$ gênero entrevista obriga a estudar a dinâmica entre esses dois elementos da interação: a pergunta, de um lado, e a reação do outro.

\section{Caso de estudo: A entrevista de Chazal na TF1}

Essa primeira entrevista, que provém do "news interview", responde, assim, a critérios de mídia, de participantes, de assuntos abordados e de duração (JUCKER, 1986), se desenvolve em quarenta e quatro turnos de fala que constituem no total 7 minutos e 53 segundos. Ela se divide, do ponto de vista estrutural, em três partes: (I) Os turnos de fala 1-6 constituem a introdução à entrevista. Nessa introdução, trata-se inicialmente de corresponder a um formato fixo, regido por formalidades e fórmulas de polidez, a saber, as saudações e o agradecimento pela recepção (GOFFMAN, 1967, p. 41; JUCKER, 1986, p. 46; WEIZMAN, 2008). Por meio do lugar onde se desenvolve a entrevista, a saber, a casa da infância da proprietária da L'Oréal, a introdução evoca a história emotiva de uma menina a quem seu pai faz falta. Um pai com quem ela tinha relações qualificadas às vezes de "simbióticas". 
EID\&A - Revista Eletrônica de Estudos Integrados em Discurso e Argumentação, Ilhéus, n. esp. ADARR, mai.2016.

Essa escolha do lugar, que não é típica do gênero entrevista de informação, a qual se desenvolve em geral no estúdio, não é anódina e preenche uma função no retrabalho da imagem. Com efeito, para a mulher de negócios, ser entrevistada no seio de seu espaço pessoal modifica a configuração do ponto de vista das relações de força, e até as inverte. Mais do que isso, o espaço específico selecionado, a saber, a casa na qual a mulher de negócios foi criada permite evocar lembranças pessoais que podem favorecer a empatia.

A parte seguinte (II) trata de vários aspectos do caso e é dividida em 8 subpartes: (1) o processo com a filha de Liliane Bettencourt (turnos de fala 712); (2) a relação de Bettencourt com Banier (turnos de fala 13-14); (3) a quantia de dinheiro exorbitante cedida a Banier (turnos de fala 15-18); (4) as gravações clandestinas e a evasão fiscal (turnos de fala 19-30); (5) a discrição como traço de personalidade de Bettencourt (turnos de fala 31-34); (6) o financiamento de partidos políticos (turnos de fala 33-34); (7) o prejuízo potencial à imagem da L'Oréal (turnos de fala 35-40); (8) uma demanda explícita de arrependimento (turnos de fala 41-42). A última parte (III) é consagrada, como exige a convenção, ao fechamento da entrevista com uma fórmula de agradecimento (turnos de fala 43-44). O cálculo dos turnos de fala consagrados a cada assunto indica que as gravações clandestinas é o assunto mais longamente abordado: doze turnos de fala. Nós nos concentramos nas 4 primeiras subpartes neste artigo.

Mas, primeiramente, eis a introdução de Liliane Bettencourt por Claire Chazal, a celébre apresentadora do telejornal que a entrevista:

A entrevista foi realizada sem a presença de um advogado ou de um conselheiro com a TF1, Bertrand Lacha et Jean-Marc Matignon [... ] Entrevista de cerca de dez minutos para a qual - vocês vão compreender rapidamente - nos limitamos a fazer perguntas de maneira muito distinta e até um pouco apoiada para facilitar a compreensão de uma mulher de 87 anos que sofre de surdez. Ouçam (grifos nossos).

Os traços destacados (a idade, a surdez) refletem tanto uma escolha deliberada da parte da jornalista quanto uma condição posta pelo conjunto dos conselheiros em comunicação. Eles veiculam a imagem de uma pessoa enfraquecida, em uma condição física ou mental suscetível de ser explorada por outros - no caso, a imagem remete indiretamente àquela que se diz vítima de um fotógrafo da alta sociedade. Sem dúvida, esses traços que implicam a fragilidade devida à sua idade são aparentemente objetivos. No entanto, a seleção da informação posta em primeiro plano - em detrimento, por 
EID\&A - Revista Eletrônica de Estudos Integrados em Discurso e Argumentação, Ilhéus, n. esp. ADARR, mai.2016.

exemplo, dos papéis sociais que dão testemunho de seu poder - prova bem que uma escolha foi efetuada. Trata-se de uma mulher que, até 2012, é a acionária majoritária da L'Oréal, o império cosmético mais conhecido do mundo, e que desempenha diversos outros papéis: mulher de negócios, ela é a mulher mais rica da França, esposa do político André Bettencourt, filha do fundador da L'Oréal Eugène Schuller (químico, conhecido também por seu financiamento da Cagoule ${ }^{5}$ e por sua colaboração com os nazistas e o antissemitismo), a herdeira única da L'Oréal, a filantropa, a mãe (de Françoise Meyer-Bettencourt) etc. Ora, a jornalista não menciona nenhum desses elementos suscetíveis de transmitir uma imagem de mulher extremamente poderosa - ao menos à época, pois a configuração mudou desde 2012. Essa introdução deliberadamente limitada e tanto mais supreendente na medida em que a entrevista ocorre próxima ao momento em que explode o "caso Bettencourt”, no qual a entrevistada está implicada na qualidade de bilionária que goza de um grande poder e tem relações com políticos influentes. Em resumo, a entrevistadora faz a escolha de reforçar a imagem da mulher frágil e vulnerável mais do que aquela de pessoa rica e poderosa.

Essa escolha significativa se efetua numa parte que é acrescentada à entrevista, ao modo de uma montagem. É, pois, à luz da informação fornecida nessa introdução que o telespectador é chamado a interpretar os pedidos de repetição das perguntas feitos pela entrevistada. É também à luz do exórdio que é solicitado ao público não se mostrar crítico demais em relação à Liliane Bettencourt, por um lado, mas também a Chazal, enquanto entrevistadora, por outro: se esta última não insiste muito sobre tal ou qual pergunta relativa às acusações lançadas contra a bilionária, é porque ela lida com uma mulher idosa e enfraquecida. Da mesma forma, se suas perguntas dão a impressão de ser colocadas de uma maneira atenuada, pode-se concluir que é por causa da idade avançada e da enfermidade de sua interlocutora.

\section{Diante do eixo familiar: a relação conflitual com sua filha}

É o discurso em torno de seu estado de saúde, colocado em primeiro plano no eixo familiar, que afeta, inicialmente, a reputação da herdeira da L'Oréal. Seu estado físico e mental tornou-se motivo de zombarias e de

5 NT: grupo de extrema direita ativo nos anos 1930, na França. 
EID\&A - Revista Eletrônica de Estudos Integrados em Discurso e Argumentação, Ilhéus, n. esp. ADARR, mai.2016.

paródias (Vovó maluca ${ }^{6}$ em Les guignols de l'info ${ }^{7}$ ). Se Liliane Bettencourt toma a palavra é, ao que parece, para manifestar que tem pleno domínio de suas faculdades. Sublinhemos que a focalização sobre essa motivação é honrosa, porque está ligada à dignidade da pessoa - procurar restaurar sua imagem em relação às acusações de corrupção é, sem dúvida, menos.

Sobre o primeiro assunto abordado, eis a primeira pergunta da entrevista na TF1:

07 C.C Então, Liliane Bettencourt, há um processo hoje entre a senhora e sua filha Françoise. É uma coisa bastante rara. Isso te faz sofrer?

08 L.B Evidentemente. Como não sofrer. É até mais do que isso. É deprimente. Porque é difícil saber a saída. É difícil... eu não gosto da palavra manobra. Mas como fazer?

09 C.C Françoise sua filha disse que ela te amava e que ela adoraria restabelecer relações com a senhora, te reencontrar. A senhora também deseja reencontrá-la?

10 L.B Evidentemente, como recusar? Mas, mas ela, você acredita que ela tentou? Eu não sinto isso.

11 C.C Ela acusa François-Marie Banier, de ter manipulado a senhora, de ter abusado de sua confiança. Você sentiu pressões por parte dele?

12 L.B Eh não... não. Mas eh eu compreendo muito bem que uma filha tenha ciúmes de sua mãe. Eu também era ciumenta com meu pai, quando eu via mulheres o rodearem. O ciúme é um sentimento que não é mau, que é verdadeiro. É o Coração. E eu compreendo muito bem que ela seja ciumenta, que eu seja também. Confessemos isso.

A entrevistadora coloca em duas retomadas a questão das relações mãefilha. Ela o faz uma vez em uma afirmação que concerne à singularidade do caso (turno de fala 08: "há um processo hoje entre a senhora e sua filha Françoise. É uma coisa bastante rara [...]”); a segunda vez, é uma afirmação relativa aos sentimentos de amor que a filha tem por sua mãe (turno de fala 10: "[...] sua filha, disse que ela te amava e que ela adoraria restabelecer relações com a senhora, te reencontrar. A senhora também deseja reencontrá-la?"). Por sua resposta, Bettencourt parece visar aos telespectadores franceses considerados numerosos pelo tipo de programa em

6 NT: O vocábulo "zinzin", traduzido aqui como "maluca", apresenta outros sentidos, sendo um deles o nome que se dá na Bolsa de Valores aos investidores institucionais. Entendemos que não se poderia desconsiderar a possibilidade do duplo sentido no emprego dessa palavra.

7 NT: "Les guignols de l'info" ou "As marionetes da informação" é um programa de televisão francês que realiza sátiras e paródias de políticos e celebridades por meio de marionetes. 
EID\&A - Revista Eletrônica de Estudos Integrados em Discurso e Argumentação, Ilhéus, n. esp. ADARR, mai.2016.

questão (um telejornal), considerando o valor partilhado de família: ela responde de modo a projetar a imagem de uma mãe desejosa de manter a relação com sua filha. Nos dois casos, ela começa por uma modalização que reforça a afirmação da entrevistadora: "Evidentemente". E logo em seguida, ela encadeia uma questão retórica ("como não sofrer", "como recusar"), que sublinha o caráter de evidência associado aos valores partilhados da família. Dessa forma, ela se mostra também guiada pelos valores que estão na base da cultura partilhada por todos os franceses, sem distinção de classe social. É o aspecto humano que é aqui colocado em primeiro plano pela entrevistadora, com quem a entrevistada se mostra cooperativa (BLUM-KULKA, 1983; JUCKER, 1986) do ponto de vista das respostas, não somente no teor de seus enunciados, mas também na modalidade de enunciação, que confirmam diretamente as proposições de sua interlocutora. A resposta da bilionária no turno de fala 08 reforça inclusive o adjetivo escolhido pela jornalista ["Como não sofrer. É até mais que isso. É deprimente" (grifos nossos)]. "Sofrer" é apresentado como um vocábulo que não é suficiente para descrever os sentimentos e o estado de aflição que a situação provoca na grande dama. Ela corrige então a escolha do termo, reforçando-o: "é deprimente", por um procedimento de amplificação que entende descrever seu sentimento de modo mais preciso. Assim, ela se mostra como sensível, calorosa, familiar, sofrendo contra sua vontade circunstâncias que Ihe são dolorosas. Uma tal apresentação é suscetível de engendrar sentimentos de empatia.

Após ter expressado seu sofrimento no que diz respeito à sua relação com sua filha, ela procede ao ataque. Sua resposta continua por um metadiscurso sobre o vocábulo "manobra" (turno de fala 08, "eu não gosto da palavra manobra. Mas como fazer?"), sublinhando o aspecto axiológico de sua utilização, colocando em evidência a falta de termos alternativos para designar o comportamento de sua filha Françoise. O que é subentendido pela palavra "manobra" nesse contexto, é que ela se relaciona com a pessoa que está aqui em questão - sua filha. Pela utilização de um vocábulo que designa um "meio hábil, astuto e mais ou menos desonesto [...]" (Dicionário Larousse), a entrevistada desacredita o comportamento de Françoise. 0 procedimento do ataque é, no entanto, atenuado pelo metadiscurso sobre o vocábulo ("eu não gosto da palavra manobra"), e pela utilização da pergunta retórica para transmitir a ideia de que não há outros termos para qualificar o comportamento de sua filha ("Mas como fazer"). Esse modo de desacreditar esta última, e assim contrariar seus argumentos a respeito de sua saúde 
EID\&A - Revista Eletrônica de Estudos Integrados em Discurso e Argumentação, Ilhéus, n. esp. ADARR, mai.2016.

degradada, prossegue no turno de fala seguinte: "Mas, mas ela, você acredita que ela tentou? Eu não sinto". Pelo conector "mas" ela eleva uma objeção (DUCROT, 1991) sobre a veracidade do conteúdo da afirmação enunciada pela jornalista, a que consiste na vontade da filha de restabelecer os laços com a mãe.

O procedimento do ataque contra aquela que é considerada como adversária, sua própria filha, prossegue no turno de fala a seguir. $\mathrm{O}$ uso do termo "ser manipulado" (turnos de fala 11-12), com relação à mulher de negócios, é um ato ameaçador para a face da entrevistada, que pode ser considerada como manipulada pelo fotógrafo, o que não é nem um pouco favorável à ideia que se possa fazer da grande mulher de negócios e convoca uma reparação de imagem. A utilização do verbo "acusar" ("Ela acusa François-Marie Banier, de ter manipulado a senhora, de ter abusado de sua confiança. Você sentiu pressões por parte dele?"), dirigido certamente contra o fotógrafo, mas que põe o acento sobre a vulnerabilidade da bilionária, apresenta uma mulher que necessita de proteção. Se a imagem de vítima de um abuso é negada por esta, a imagem de uma mulher fragilizada não deixa de emergir de tempos em tempos tanto em seus enunciados quanto em sua enunciação (a falta de entendimento). Esse procedimento pode confundir sobre seu estado de saúde efetivo e assim desresponsabilizar a grande dama em outros aspectos do caso.

É, pois, em relação à imagem aviltante de uma mulher manipulada, que Bettencourt coloca em primeiro plano um argumento de causalidade que trata dos motivos de sua filha a apresentar sob essa luz: trata-se do ciúme de Françoise que a levaria a manter tal discurso em relação à mãe. Ela desacredita assim, à base de motivos psicológicos, a acusação que diz respeito às relações com o fotógrafo e nega o fato de que ela seja manipulável. $O$ ataque, entretanto, se efetua de maneira a não se dar abertamente como tal, pois Bettencourt atenua o erro de Françoise, admitindo seu próprio sentimento de ciúme em relação a seu pai, e apresentando esse tipo de atitude como natural. Desse modo, ela se mostra compreensiva: ela é uma pessoa dotada de maturidade que aceita os sentimentos humanos tratados como "verdadeiros", e sobretudo uma pessoa de grande lucidez. É precisamente por sua lucidez em nível intelectual e psicológico que ela busca retificar a sua imagem propagada pelas acusações de sua filha acerca da doação extremamente generosa feita a um fotógrafo de seus amigos. 
EID\&A - Revista Eletrônica de Estudos Integrados em Discurso e Argumentação, Ilhéus, n. esp. ADARR, mai.2016.

\section{Eixo familiar: a acusação sobre as doações a Banier}

Além do estado mental da bilionária, o eixo familiar levanta um tema que, se é, em princípio, privado, deixa de sê-lo a partir do momento em que o caso estoura: a quantia de dinheiro faraônica concedida pela bilionária a Banier. Enquanto o conflito entre mãe e filha não exigia necessariamente justificação perante o grande público, não acontece o mesmo com respeito à doação. A animadora do telejornal aborda no turno de fala 15 a reprovação dirigida a Bettencourt acerca desse assunto:

15 C.C Falou-se, Liliane Bettencourt, de quantias significativas que a senhora deu a ele ou que a senhora lhe teria dado. A senhora compreende que a opinião pública possa, eh.., estar surpresa por essas quantias? (grifos nossos)

L.B Eu entendo muito bem. Mas então? É preciso que eu a retome? Você vê? Será que a gente não doa coisas na vida... É preciso sempre contar quando se pode nem tudo contar? (grifos nossos)

O tema do dinheiro constitui a primeira pergunta contendo um desafio para Bettencourt. Para muitos franceses, saber que a doação de Bettencourt a uma pessoa próxima se eleva a várias centenas de milhões de euros, e até mesmo um bilhão, é sentido como uma espécie de afronta. Enquanto o comum dos mortais trabalha muito duro para completar sua renda, eis que a mulher de negócios se permite um gasto excessivo que suscita a indignação, despertando o sentimento de desigualdade e de injustiça. Fazer uma pergunta que suscita uma viva indignação constitui em si uma ameça para a face da entrevistada; implica uma reprovação à qual se espera que ela reaja.

A formulação "estar surpresa" constitui uma observação ameaçadora, embora atenuada em relação a outros verbos possíveis. É um termo que convoca um comportamento linguageiro de reparação da imagem da parte daquele que cometeu o ato que surpreende. À lista de marcadores de desafio ou de "estratégia de confrontação", estabelecida por Owsley e Myers-Scotton (1984), que inclui o uso de "but, however, yet, still (but), while, what about, [or] why not" (Ibidem, p. 266), aos quais nós acrescentaremos os verbos com potencial de desafio, como "estar surpreso" (e mais abaixo "estar chocado"). Como mencionaram McLaughlin, Cody e Rosenstein (1983), a expressão da surpresa ou do desgosto constitui um dos quatro tipos de reprovação ou de asserção que provocam explicações ou pedido de desculpas. Em outros termos, o sentimento de surpresa por parte da opinião pública é um marcador 
EID\&A - Revista Eletrônica de Estudos Integrados em Discurso e Argumentação, Ilhéus, n. esp. ADARR, mai.2016.

de crítica: o fato de que a opinião pública esteja surpresa deve provocar uma reação de arrependimento ou de explicação. Donde a necessidade de uma das estratégias mencionadas em Jucker $(1986, \text { p. } 89)^{8}$, que convoca uma justificação relativa ao ato pelo qual a pessoa é considerada responsável e cuja natureza é efetivamente prejudicial.

Assim Bettencourt é solicitada a reagir a uma reprovação que comporta dois elementos de desafio: a enormidade da quantia e o ato, considerado ofensivo, de concedê-la numa época de crise, Pode-se ler em filigrana que só se oferecem tais quantias se se sofre de uma perturbação mental ou se alguém se aproveita de você. As insinuações inscritas no enunciado "a opinião pública possa, eh.., estar surpresa por essas quantias?” são degradantes para a imagem da mulher de negócios, e é em relação a elas que se espera que ela responda.

O desafio que Chazal lança a Bettencourt concerne ao seu papel social enquanto proprietária da L'Oréal, bilionária e filantropa. Esses papéis implicam obrigações (WEIZMAN, 2008): aquelas provenientes do papel de mulher mais rica da França seriam fazer doações aos mais desamparados, não exibir doações com as quais o comum dos mortais não pode sequer sonhar, e isso, sobretudo, em período de grave crise econômica. Enquanto entrevistadora, espera-se que Chazal desempenhe, em seu papel social como jornalista, mas também em seu papel interacional, aquela que representa a opinião pública (KOREN, 1996) para quem a entrevista acontece. Ela se encontra, portanto, na obrigação de lhe fazer essa pergunta, que contém inevitavelmente um desafio para a face de sua entrevistada.

Entretanto, o desafio posto por Chazal é extremamente atenuado. No âmbito desse turno de fala, encontramos diversas formas de atenuação: a qualificação do pomo da discórdia (o dinheiro) pelo qualificativo "significativa" - um bilhão de euros pode ser qualificado como quantia colossal. Uma outra formulação atenuante encontra-se na formulação no condicional passado ("Falou-se, Liliane Bettencourt, de quantias significativas

8 Jucker estabelece uma escala de estratégias indo da menos ameaçadora [1] para a mais ameaçadora [13]. No original: "Strategy [10], as well as strategy [9], takes the occurrence and the demeaning nature of the action or event for granted but unlike strategy [9] it also takes the interviewee's responsibility for granted. Strategy [10] asks for a justification of the action".

"A estratégia [10], assim como a [9], considera como garantida a ocorrência e a natureza degradante da ação ou do evento, mas, diferente da estratégia [9], ela também toma por certa a responsabilidade do entrevistado. A estratégia [10] pede uma justificativa para a ação" (tradução livre). 
EID\&A - Revista Eletrônica de Estudos Integrados em Discurso e Argumentação, Ilhéus, n. esp. ADARR, mai.2016.

que a senhora deu a ele ou que a senhora lhe teria dado"). Trata-se bem de uma tendência a atenuar, pelo uso da linguagem, o que pode ser percebido como provido de um forte potencial de desafio.

A atenuação pode servir para transmitir um ethos de jornalista ponderada que incita a entrevistada a cooperar. Ao mesmo tempo, a entrevistadora intenta veicular uma imagem neutra: a escolha de uma formulação atenuante projeta um ethos de jornalista moderada e equilibrada, que se recusa a tudo o que seria sensacional ou provocador. Ora, se, segundo Perelman e Olbrechts-Tyteca (2008, p. 618), "as técnicas de atenuação dão uma impressão favorável de ponderação, de sinceridade [...]", elas podem ser consideradas inversamente como procedimentos de complacência da parte de jornalistas com pessoas da alta sociedade que deveriam ser abordadas de maneira mais robusta. A escolha do vocábulo atenuante "significativa" para a quantia de dinheiro poderia assim provocar a crítica dirigida à jornalista indulgente demais com sua entrevistada, e até mesmo a repreensão de cooperar com a classe dominante ${ }^{9}$. Uma das funções do eufemismo é a redução do desafio potencial existente inevitavelmente nas perguntas que tocam as circunstâncias em razão das quais a entrevista ocorre. O uso da atenuação faz com que Chazal seja percebida como uma "jornalista complacente"10.

A atenuação é duplicada por outro procedimento discursivo que consiste no apagamento enunciativo (KERBRAT-ORECCHIONI, 1980; KOREN, 1996) da jornalista. A forma impessoal da formulação permite à jornalista se refugiar por trás de uma forma abstrata, de modo que a crítica é enunciada de uma maneira impessoal: em "falou-se", encontramos o pronome que podemos interpretar como um indefinido impessoal (FLOTTUM, JONASSON e NORÉN, 2007, p. 30), por trás do qual Chazal enquanto pessoa se apaga, deixando falar uma voz impessoal que pode ser referida ao grande público e aos meios de comunicação. Ela consegue assim dar voz ao público, como quando ela evoca a opinião, e a transmitir a reprovação sem assumir a responsabilidade por isso. O apagamento enunciativo pode assim, em certo nível, conservar a face da

9 É efetivamente uma das críticas lançadas contra ela após a veiculação da entrevista. E isso tanto mais que segundo seus críticos as duas mulheres se conhecem por intermédio de amigos comuns.

10 Esse caso é percebido como uma ilustração daquilo que é considerado na esfera pública do "jornalismo de complacência"». Assim, podemos encontrar reações de internautas como aquela que lemos no Huffington Post, após o artigo publicado no Le Parisien assinado 1234567, dia 3/7/2010: "Que pena que Claire Chazal se tenha deixado embarcar nessa mascarada". Ou ainda, aquela assinada por Eric Claxon: "Claire Chazal conta sua entrevista com Liliane Bettencourt! A quantia do cheque continua 50.000 euros?" Assim como o artigo em Mediapart "TF1 faz projetos ambiciosos para Liliane Bettencourt", por Michael Hajdenberg, dia 2/7/2010. 
EID\&A - Revista Eletrônica de Estudos Integrados em Discurso e Argumentação, Ilhéus, n. esp. ADARR, mai.2016.

entrevistadora, assim como veicular uma recusa em assumir a responsabilidade.

Embora ela comece sua resposta em um tom compreensivo, a entrevistada parece recorrer a estratégias de restauração da imagem sob a forma de uma autolegitimação relativa a seu status de bilionária ("Eu entendo muito bem. Mas então? É preciso que eu a retome? Você vê? Será que a gente não doa coisas na vida... É preciso sempre contar, quando se pode nem tudo contar?"). Ora, contrariamente às expectativas que subjaziam a pergunta de Chazal, a saber, uma marca de empatia ou de solidariedade da parte de Bettencourt em relação aos sentimentos do grande público, a bilionária insiste justamente em suas imensas capacidades financeiras. De início, a "grande afortunada" não nega ter dado dinheiro, e ela não dá mostras de nenhum arrependimento em relação a seu ato, nem manifesta nenhum sentimento de incômodo. Certamente, ela pronuncia o enunciado "Eu entendo muito bem", mas isso constitui uma concessão - um modo de falar desprovido de significação verdadeira; talvez ela responda com essa formulação pelo fato de que a pergunta é formulada nestes termos (“A senhora compreende?"), oferecendo, assim, em sua enunciação, uma marca de cooperação com sua interlocutora.

Por outro lado, a sequência do enunciado rompe com essa cooperação, pois, logo a seguir, ele introduz o conector "mas [então?]”. Esse vocábulo muda o tom e exprime uma oposição (DUCROT, 1991) em relação ao que acaba de ser declarado, ao mesmo tempo em que dá mais importância à proposição que o segue (AMOSSY e HERSCHBERG PIERROT, 1997). Se ela entende muito bem que a opinião pública esteja surpresa, ela deve oferecer uma explicação qualquer. O que não acontece. Essa falta de justificação diante do grande público revela uma atitude pouco solidária e desprovida de empatia face àqueles que, contrariamente a ela, não nadam em dinheiro.

Há mais. A resposta de Bettencourt concentra-se na ideia de que se trata de um fato consumado que é impossível de modificar - portanto, sobre o comportamento esperado dela nesse momento. Ora, não é sobre isso que trata a questão. O mas então permite supor que ela aceita a reprovação por ter dado uma quantia desproporcional, deslocando o acento para as consequências práticas de tal reconhecimento, que são, de todo modo, nulas - o arrependimento não pode levar a nada, portanto, a reprovação, nesse momento, não serve para nada. 
EID\&A - Revista Eletrônica de Estudos Integrados em Discurso e Argumentação, Ilhéus, n. esp. ADARR, mai.2016.

Em seguida, a entrevistada coloca um desafio à entrevistadora, sob a forma de uma pergunta retórica: "é preciso que eu a retome?". Pergunta cuja resposta supõe-se ser negativa, uma vez que, como se sabe, não se retomam presentes depois que já foram entregues. A essa pergunta retórica se junta uma dimensão de absurdo que é reforçada pela pergunta "você vê?", como para significar "você vê que o que você me pergunta é absurdo". A insinuação de que a pergunta feita é absurda e de que ela se contrapõe a normas das boas maneiras lança um desafio a Chazal em seu papel interacional de entrevistadora assim como em seu papel de jornalista.

Enfim, nessa resposta, a entrevistada enuncia a premissa maior de um silogismo truncado ("É preciso sempre contar, quando se pode nem tudo contar?"). Trata-se de um entimema, do qual podemos reconstruir o silogismo da maneira seguinte: Premissa maior: Os ricos podem nem tudo contar. Premissa menor: Bettencourt é rica. Conclusão: Bettencourt pode não contar suas doações. O fato de enunciar unicamente a premissa maior, que se apresenta como uma verdade que não se pode refutar, e ainda sob a forma de uma pergunta retórica, torna difícil uma argumentação ou uma acusação a esse respeito. E, portanto, a conclusão, que decorre do raciocínio do qual Bettencourt não formula a premissa menor que a concerne, evidentemente. É por esse enunciado - insistindo em sua possibilidade de não contar o que ela oferece - que ela se dá a legitimidade de cometer o ato julgado repreensível. Além disso, o emprego do verbo "contar" tem aqui conotações pejorativas, pois aqueles que contam sem parar não são generosos. Ora, é justamente esse enunciado que acentua as disparidades sociais e a falta de solidariedade ou de consideração face aos sentimentos do público.

A entrevistadora considera que a resposta de Bettencourt não é da ordem da justificação esperada, e refaz a pergunta:

17 C.C Você compreende que a opinião pública esteja surpresa, chocada nestes períodos de crises. <há uma disparidade...> (grifos nossos)

18 L.B <Chocada pelo quê?! > Diga-me, chocada pelo quê? Porque eu dei dinheiro? Mas isso é infantilismo. É um país que conta, é um negócio que conta, são pessoas que trabalham que contam. O resto raus"1! (grifos nossos)

A jornalista não se contenta, portanto, de ter levantado uma vez o problema do dinheiro dilapidado: ela refaz a pergunta retomando o

11 Em alemão: "fora". 
EID\&A - Revista Eletrônica de Estudos Integrados em Discurso e Argumentação, Ilhéus, n. esp. ADARR, mai.2016.

qualificativo "surpresa" acerca da opinião pública, reforçando desta vez o desafio inicialmente atenuado, pelo uso de um qualificativo mais forte: "chocada", que se junta à lista dos marcadores de desafio mencionada mais acima. Esse duplo reforço indica a necessidade de receber uma resposta de natureza informacional e uma reação mais cooperativa ("supporting", segundo o termo de BLUM-KULKA, 1983; JUCKER, 1986, p. 50); esse imperativo deriva do papel da jornalista que está ciente das expectativas do público. Trata-se de uma demanda de justificação, podendo ser também considerada como uma ameaça direta à face de Bettencourt, pois ela coloca diretamente a pergunta relativa ao dano à sua imagem aos olhos do público. À repetição do vocábulo e à menção de um verbo mais forte ("chocada") se junta uma especificação relativa ao contexto social e econômico do país e do mundo ("[...] nestes períodos de crises. <Há uma disparidade...>"). Em outros termos, o contexto de crise é a razão pela qual o francês espera um comportamento solidário por parte de seus dirigentes, inclusive no domínio econômico. A explicitação da questão subentende que Bettencourt não compreende realmente todas as implicações - o sentido de seu ato em período de crise, assim como a disparidade que ele marca entre sua grande fortuna e os recursos dos outros.

Ora, a entrevistada não apresenta a resposta desejada para apaziguar os sentimentos de hostilidade do público. Ela interrompe a pergunta de Chazal, manifestando assim seu descontentamento face a esse quetionamento insistente. Ela dá mostras de aborrecimento face à qualificação de "chocante" aplicada a seu comportamento próprio, que parece convocar uma justificação de sua parte para apaziguar o "espanto" ou o "choque".

Embora a grande afortunada não forneça reação adequada com relação às expectativas de solidariedade, ela recorre, no entanto, a procedimentos dentre os quais alguns podem ser considerados como tentativas de restauração da imagem. As modalidades de apresentação da questão ativam no discurso de Bettencourt cinco procedimentos discursivos: inversão da questão e um tipo de negação, estratégia de minimização, uma injúria, estratégia de reforço da empresa apagando-se por trás dela, e enfim distinção implícita entre a esfera privada e a esfera pública.

A grande dama reage, inicialmente, colocando duas vezes uma questão (“Chocada pelo quê?”) que revela seu próprio espanto acerca da reação do público: por um efeito de retorno, ela se espanta com o fato de que o público 
EID\&A - Revista Eletrônica de Estudos Integrados em Discurso e Argumentação, Ilhéus, n. esp. ADARR, mai.2016.

esteja tomado por um sentimento de choque. Assim ela deixa entender que essa reprovação não tem razão de ser, porque não há aí nada de repreensível. Nesse caso, trata-se de uma estratégia de negação que desmente que o ato seja um erro (AUSTIN, 1961, p. 124). Mas também, ela acrescenta que se trata de um comportamento proveniente da esfera privada. Bettencourt procede desse modo por uma distinção entre o que pertence à esfera pública e à esfera privada. Essa concepção é visivelmente oposta àquela que apresentou a jornalista e que circula no espaço público. Para a grande afortunada, o fato de ter dado dinheiro constitui um negócio puramente privado que não concerne ao público. É isso que é indicado por meio da expressão "o resto... raus!". Por essa formulação, marcada de violência (sobretudo em sua transição para a língua alemã e as conotações que isso pode provocar), entende-se não somente que tudo aquilo que não concerne a empresa não é pertinente, mas também que ela expulsa todos aqueles que querem penetrar em seu domínio privado. Ela opera assim uma redefinição daquilo que participa a cada uma das esferas, redefinindo as fronteiras entre o espaço privado e o espaço público. Ora, aquilo que ela considera proveniente da esfera privada não é visivelmente considerado como tal pelos meios de comunicação e pelo público. Há aqui, pois, um conflito de pontos de vista que provoca a reação polêmica (AMOSSY, 2014) de Bettencourt. A insistência de Chazal conduz assim a uma explicitação da oposição de posições respectivas. Notemos que nessa redefinição das fronteiras entre o privado e o público, Bettencourt dá prova uma vez mais de uma grande presença de espírito e de um senso da réplica, mesmo quando ela se deixa levar pela cólera.

Entretanto, embora ela deslegitime a questão e a reprove, ela fornece, mesmo assim, uma reação que é considerada na literatura científica como visando à reparação da imagem: ela minimiza o ato. Isso se traduz, de início, na expressão de um espanto relativo ao fato de que se possa ficar chocado por uma doação de dinheiro (chocado pelo quê? porque eu dei dinheiro?). Notemos que ela não menciona a quantia em questão, ao passo que é seu caráter desmedido que coloca o problema. Assim a técnica de dissimulação dos fatos se põe a serviço da estratégia de minimização. A eficácia dessa última pode, no entanto, ser considerada como contestável na medida em que o montante da quantia cedida é conhecido por todos.

A minimização do ato grave se transforma na sequência em um ato de insulto: "Mas isso é um infantilismo". Bettencourt procede por um ataque 
EID\&A - Revista Eletrônica de Estudos Integrados em Discurso e Argumentação, Ilhéus, n. esp. ADARR, mai.2016.

que visa a desqualificar a tese, a saber, a acusação colocada contra ela, assim como aquele que adere a ela (tese). A desqualificação se faz na base da acusação de regressão mental, ou seja, de um defeito de desenvolvimento ligado ao emprego de "infantil". Bettencourt, acusada de senilidade e de incapacidade intelectual, inverte aqui a acusação contra aqueles que the fazem repreensões. Ela entende que eles não são capazes de um pensamento maduro suscetível de estabelecer uma reflexão racional. Isto para introduzir pouco depois uma outra focalização sobre aquilo que deve determinar as prioridades.

$O$ argumento que determina a prioridade do que deveria interessar ao público é aquele que mobiliza a multinacional L'Oréal, assim como o fato de que os assalariados se beneficiam dela. Fazendo isso, a mulher de negócios reforça indiretamente sua imagem enquanto proprietária de uma empresa muito importante (estratégia de reforço), sublinhando outro aspecto de sua atividade: ela proporciona empregos. $\mathrm{O}$ recurso a elementos relativos à multinacional tem por finalidade realçar suas funções positivas na imagem de sua acionista principal, e de reforçar assim sua legitimidade. Ao mesmo tempo, mobilizar esse argumento permite desviar a atenção das questões evocadas pela jornalista, e apagar o indivíduo por trás da empresa. $O$ fato de modificar o centro de interesse e de colocar o acento sobre as benfeitorias que a firma traz aos franceses supõe afastar os temas que não provêm do espaço público. A resposta cria uma hierarquia: a quantia de dinheiro doada no interior da esfera privada não tem a mesma importância que o bom funcionamento de uma multinacional que proporciona benfeitorias aos franceses sob a forma de postos de trabalho e de impostos depositados no caixa público.

Essa dinâmica mostra bem que desde o início cada uma das participantes tenta defender seu próprio ethos: a jornalista enquanto aquela que faz perguntas quentes com respeito ao caso considerado como "[...] um dos maiores escândalos da $5^{\text {a }}$ República" (ARFI e LHOMME, 2010, p. 9); a entrevistada, enquanto uma mulher de negócios poderosa e uma pessoa lúcida dotada de todas suas faculdades intelectuais.

Bettencourt, por suas reações, trabalha para minar a legitimidade das perguntas, que ela converte em ridículas, sobre a extensão extravagante dos bens. Reagindo à sua representação desfavorável como pessoa diminuída e manipulada, ela visa a modificar essa impressão por seu ethos mostrado 
EID\&A - Revista Eletrônica de Estudos Integrados em Discurso e Argumentação, Ilhéus, n. esp. ADARR, mai.2016.

(MAINGUENEAU, 1996, p. 40), que se constrói por meio de seus argumentos e da colocação em primeiro plano de seus papéis sociais. Ela procede pelo reforço de seus traços positivos por intermédio da empresa que possui. Ela dá mostras de uma atitude de naturalmente eleita enquanto herdeira de um império e de mulher mais rica da França. Esses papéis lhe conferem características que a diferenciam de um ser humano comum. Nesse sentido, nós podemos fazer uma relação com o que Kantorowicz (1997) nomeia "os dois corpos do rei”. Há expectativas da parte da jornalista que concernem essa "representação simbólica"12 (COULOMB-GULLY, 1999, p. 205) de Bettencourt, isto é, seu corpo simbólico e não pessoal, que ela seja portadora de um conjunto de valores, como por exemplo a benfeitoria com o grande público, ou que se espera que ela não se mostre indiferente diante da miséria. Contrariamente às expectativas, Bettencourt exprime por sua incompreensão um distanciamento do público, e um posicionamento social fundado sobre a distinção. Ela dá mostras de uma falta de solidariedade, um valor derivado, exigido também pelos dois valores inscritos sobre a divisa republicana "[liberdade], igualdade, fraternidade". Ela rejeita totalmente a legitimidade da questão. Fazendo isso, ela faz lembrar a atitude de outra (verdadeira) rainha que propôs que o povo comesse brioches se não houvesse mais pão.

As duas interlocutoras debatem sobre o fundo, sobre os valores que se supõe guiar os atos da dirigente econômica. Enquanto na base do discurso da mulher de negócios se encontra o valor da liberdade, a saber, que ela é livre enquanto indivíduo para fazer o que ela deseja com seu dinheiro, e que ela não é obrigada a prestar contas, a jornalista a confronta com um outro valor: 0 de solidariedade. Esse valor é uma manifestação de igualdade, que é subentendida pela pergunta de Chazal, e que dita igualmente as expectativas do público.

Em resumo, a reação de Bettencourt face à reprovação de extensão do dinheiro e àquela subentendida de falta de solidariedade, repousa sobre a estratégia de reforço das benfeitorias da L'Oréal, sublinhando o interesse público que consiste em preservar essa empresa e a necessidade de apreciá-la. Assim, ela se apaga por trás da firma, fazendo crer que ela, enquanto pessoa, não é o assunto de que importa tratar. Posicionar-se como secundária, determinando as prioridades que devem ser as do público, constitui uma

12 Nós aplicamos aqui essa noção sobre a bilionária, embora Coulomb-Gully a utilize para os políticos. 
EID\&A - Revista Eletrônica de Estudos Integrados em Discurso e Argumentação, Ilhéus, n. esp. ADARR, mai.2016.

espécie de estratégia de desvio da atenção para evitar abordar os aspectos problemáticos do caso que concerne Bettencourt.

\section{O eixo fiscal: diante do tema das gravações que evocam a evasão fiscal}

A subparte seguinte no âmbito da entrevista com Chazal trata do eixo do caso que implica o regime no poder. A parte precedente evocou a relação entre a bilionária e sua filha, assim como com o fotógrafo Banier, temas que podem ser considerados como provenientes do domínio privado. Nesse espaço, a pessoa não é necessariamente requerida para proporcionar as respostas exigidas ou de prestar contas. Temos, entretanto, mostrado que aquilo que é percebido por Bettencourt como proveniente do privado é considerado pelos jornalistas como de interesse geral. Por outro lado, nos dois outros eixos do caso, o eixo fiscal e político, revelados pelas gravações clandestinas, trata-se de acusações que concernem, por definição, ao interesse público, a bem dizer. Nós vamos abordar agora a maneira pela qual a acusação relativa à evasão fiscal é tratada por meio das reações da mulher de negócios:

19 C.C Ocorreram, Liliane Bettencourt, gravações clandestinas de suas conversas. Hoje isso te choca, que essas gravações sejam publicadas?

20 L.B Sim, evidentemente. Evidentemente. Mas... (levantamento dos ombros) se é preciso fazer, será feito.

21 C.C Mas, nessas gravações, trata-se de evasão fiscal. A senhora estava a par disso?

22 L.B De ?

23 C.C Do fato de que havia, em seu nome, contas no exterior? Na Suíça, por exemplo?

24 L.B Ouça, nós temos muitos negócios no exterior, nós trabalhamos muito com nossos negócios no exterior. $\mathbf{O}$ que isso quer dizer, alguma coisa no exterior? É claro que temos negócios, temos imóveis, temos ... quando montamos negócios, não estamos falando de uma loja.

O tema relativo à evasão fiscal é abordado pela menção do sobrenome e do nome da entrevistada "Liliane Bettencourt". A utilização desse modo de nomeação formal, que constitui um marcador de desafio relativo a um conflito (WEIZMAN, 2008, p. 117), indica, da parte da entrevistadora, que ela vai introduzir um assunto que vai ao encontro das opiniões da entrevistada (CLAYMAN e HERITAGE, 2002, p. 250). Ora, embora as perguntas contenham 
EID\&A - Revista Eletrônica de Estudos Integrados em Discurso e Argumentação, Ilhéus, n. esp. ADARR, mai.2016.

desafios por sua própria natureza, assim como pelo emprego de termos de tratamento formais, elas são formuladas de uma maneira delicada que atenua essas ameaças inevitáveis. A entrevistadora coloca o acento sobre o aspecto afetivo, e não factual, da acusação: ela demanda a conhecer o sentimento de Bettencourt sobre as gravações que ocorreram sem o seu conhecimento. A maneira pela qual a pergunta é feita opera uma atenuação considerável do desafio lançado à grande dama: ela se focaliza no que ela sente e não numa explicação relativa à acusação. A atitude sensível (que se exprime nas formas atenuantes das perguntas) da qual dá mostras Chazal é, no entanto, justificada por ela desde a introdução, como vimos, para evitar ser tachada de complacente. Sua formulação é ambígua; é possível compreender isso, seja pelo viés técnico (o fato de estar gravado: isso choca a senhora, de ter sido gravado?) seja pelo viés do conteúdo (isso choca a senhora que o que a senhora disse tenha sido gravado?). A formulação equívoca permite à entrevistada responder seguindo sua própria agenda.

Bettencourt responde, portanto, pela afirmativa. Essa maneira de aprovar o vocábulo afetivo (chocar) marca, aparentemente, a cooperação da entrevistada na interação. Não admitir que ela seja atingida emocionalmente por essas gravações, que, além disso, foram publicadas e das quais o público dispõe, arrisca mostrá-la sob uma luz problemática. Entretanto, a imprecisão ("será feito") que predomina na resposta da entrevistada não permite saber a que ela respondeu (o que será preciso fazer). Acrescenta-se a isso o emprego de um on específico e inclusivo (FLOTTUM, JONASSAN e NORÉN, 2007), em francês, no lugar de um je claramente definido. A técnica da imprecisão, assim como as duas ocorrências que seguem exprimindo a falta de entendimento da entrevistada, podem ser consideradas tanto como manifestações de problemas psicológicos quanto um meio de esquivar as acusações a seu respeito ${ }^{13}$.

Embora a formulação atenue as ameaças para a face de Bettencourt, a entrevistadora busca, ao menos em aparência, mostrar que ela levanta questões ardentes que concernem ao caso. É assim que, com relação à

13 Em um dossiê intitulado "L'étrange bonne fortune de Liliane" ["A estranha boa fortuna de Liliane"] no Nouvel Observateur número 2456, datado de $1^{\circ}$ de dezembro de 2011 , acrescenta-se um artigo de Jacqueline de Linares intitulado "Quand les soignants et les soignés trichent. La fraude nuit gravement à la santé" [ "Quando os cuidadores e os que recebem cuidados trapaceiam. A fraude prejudica gravemente a saúde” ], p.128. A acoplagem do artigo e o assunto do dossiê, a saber, as contas suíças de Liliane Bettencourt, transmitem a concepção da redação a respeito do dito estado de saúde da herdeira da L'Oréal. 
EID\&A - Revista Eletrônica de Estudos Integrados em Discurso e Argumentação, Ilhéus, n. esp. ADARR, mai.2016.

resposta vaga de Bettencourt, suscetível de ser considerada como nãocooperativa, ela demanda à entrevistada (turno de fala 20) uma "extensão do assunto" (BLUM-KULKA, 1983; JUCKER, 1986, p. 47), no caso, uma resposta mais explícita. Chazal dá mostras de uma tentativa de esclarecer mais a pergunta sublinhando o conteúdo revelador das gravações, a saber, a evasão fiscal (turno de fala 21: "Mas, nessas gravações, trata-se de evasão fiscal. A senhora estava a par disso?”) Começando efetivamente a pergunta com um articulador, "mas", considerado como um dos marcadores de desafio, segundo Owsley e Myers-Scotton (1984), Chazal manifesta sua vontade de ter mais informação: ela exprime um julgamento com relação à resposta precedente considerada insuficientemente informativa, e até mesmo evasiva. Ao mesmo tempo, a pergunta que segue a afirmação a respeito da acusação (evasão fiscal) deixa à entrevistada uma saída de emergência: ela pode afirmar não ter ficado sabendo.

Ora, em relação a certas perguntas, das quais uma concerne justamente à evasão fiscal, a entrevistada utiliza um procedimento discursivo que consiste no pedido de repetição da pergunta ou de esclarecimento (KERBRATORECCHIONI, 2010 [1990], p. 19). Ela manifesta uma lacuna de entendimento que chama a entrevistadora a reiterar sua interrogação, como se ela afirmasse ter "um problema comunicativo"14 (Ibidem). Ela procede, para isso, enunciando a preposição "de" sob forma de interrogação (turno de fala 22), o que é também um tipo de pedido de correção ${ }^{15}$ (SCHEGLOFF, JEFFERSON e SACKS, 1977, p. 367). Diante de uma reformulação que consiste na correção da expressão "evasão fiscal", inicialmente enunciada na pergunta de Chazal, ela modifica o termo ampliando o alcance do enunciado: "do fato de que havia, em seu nome, contas no exterior" (turno de fala 23). A evasão fiscal torna-se assim "contas no exterior". Enquanto a evasão fiscal, sendo uma expressão

14 Ela o faz claramente em uma curta entrevista na FR3 de 15.07.2010, em que ela diz não entender bem e não se lembrar quando se trata de perguntas incômodas. Segundo a jornalista da FR3, citada no programa "Complément d'enquête», veiculado por France 2, dia 31 de outubro de 2013: "Assim que abordamos as perguntas sobre financiamento, as perguntas de reações políticas, as perguntas inclusive de fraude fiscal e tudo mais, ela tentou evadir, isso lhe passa por cima da cabeça, e ela joga um pouco com sua surdez. Ela me faz repetir, sim, ela responde de lado. No geral eu a aborreço para falar dessas coisas. Sentimos bem que são coisas que nem lhe interessam nem lhe são importantes" (0:55:14). Segundo essa análise da jornalista, trata-se de uma estratégia que consiste em se mostrar mais fraca do que ela é, e de contribuir à incerteza que reina sobre seu estado de saúde.

15 Esse procedimento discursivo consiste no pedido de um dos interlocutores ao outro para que corrija sua enunciação: “[... ] replacement of an 'error' or 'mistake' by what is 'correct"” (Ibidem, p. 363). Aqui nós a encontramos no pedido de corrigir o que o interlocutor pensa como um erro, isto é, como elemento que possa conduzir a uma visão equivocada dele. Esse pedido pode se manifestar sob diferentes formas (ah?, repetição das mesmas palavras do interlocutor etc.) 
EID\&A - Revista Eletrônica de Estudos Integrados em Discurso e Argumentação, Ilhéus, n. esp. ADARR, mai.2016.

ambígua, pode ser legal ou ilegal, mas em todo caso uma prática combatida e considerada como repreensível (sobretudo quando se trata de fraude fiscal), as contas no exterior são completamente legais tanto no plano jurídico quanto no plano fiscal (sob a condição de que as quantias sejam declaradas). Assim, o procedimento da jornalista neutraliza mais o desafio que continua presente na possibilidade de ter contas no exterior. Com efeito, embora existam diferentes paraísos fiscais, a jornalista dá como exemplo a Suíça; ora, a Nestlé, uma das primeiras multinacionais agroalimentares do mundo, se situa na Suíça e detém $23.29 \%$ das ações da L'Oréal. É, pois, evidente que a multinacional entretém relações com a Suíça. Assim, a reformulação engendrada por uma marca discursiva de falta de compreensão da parte da entrevistada, suaviza, consideravelmente a ameaça que contém a expressão "evasão fiscal" (que difere da fraude fiscal), e facilita, dessa forma, o trabalho de restauração da imagem. Em seguida, Bettencourt deixa de responder a um dos elementos contidos na pergunta: o que indica contas privadas "em seu nome" ("Havia, em seu nome, contas na Suíça”). A entrevistadora não insiste. Essas duas manobras permitem a Bettencourt responder de modo a proteger sua face aí onde ela é apresentada como um agente corruptor.

A partir do momento em que ela mobiliza (deliberadamente ou espontaneamente) a imagem da mulher idosa a quem falta o entendimento, é a imagem da mulher de negócios poderosa que é posta em causa. Ora, paralelamente, ela emprega procedimentos que remetem ao ethos, ao mesmo tempo, de uma mulher forte intelectualmente e de uma mulher de negócios. Bettencourt responde (turno de fala 24: "Ouça, nós temos muitos negócios no exterior, nós trabalhamos muito com nossos negócios no exterior. $\mathbf{O}$ que isso quer dizer, alguma coisa no exterior? É claro que temos negócios, temos imóveis, temos... quando montamos negócios, não estamos falando de uma loja”.) de tal modo que ela aponta uma suposta evidência: eles têm contas no exterior, uma vez que eles trabalham com o exterior na qualidade de multinacional, tendo, por definição, filiais em outros países. Não somente ela pretende dizer o óbvio de modo aparentemente transparente, mas também ela contesta a formulação da jornalista a esse respeito.

Entretanto, o que Bettencourt reformula não é exatamente o que a jornalista enunciou. Se essa última utilizou o substantivo "contas [no exterior]", a grande dama, de sua parte, entende o pronome indefinido "alguma coisa" (“O que isso quer dizer, alguma coisa no exterior?". Como a 
EID\&A - Revista Eletrônica de Estudos Integrados em Discurso e Argumentação, Ilhéus, n. esp. ADARR, mai.2016.

jornalista indica a surdez da grande dama desde a introdução, o deslizamento entre "contas no exterior" (suficientemente suspeito) a "alguma coisa" (neutro, mas geral) se opera naturalmente, sem que o telespectador possa se dar conta. Ora, mesmo o termo neutro, mas geral, tendo por efeito a redução da ameaça para a face de Bettencourt, é contestado por esta. Não é "alguma coisa" que Bettencourt tem no exterior, mas bem um império multinacional, um negócio sério.

A figura retórica da litote que ela utiliza ("não estamos falando de uma loja") marca a disparidade com o império que constitui a L'Oréal. A entrevistada introduz um termo que é o inverso daquele que utilizaríamos para qualificar o império L'Oréal, para imediatamente rejeitá-lo. A figura da litote exige efetivamente "[...] que o ouvinte conheça certo número de dados que o guiarão em sua interpretação" (PERELMAN e OLBRECHTS-TYTECA, 2008 [1958], p. 393). Como se trata de uma multinacional francesa, a mais conhecida, que é o oposto de uma loja, a observação ridiculariza a questão da entrevistadora. A declaração irônica segundo a qual se trata de negócios de verdade desafia a pergunta de Chazal e arrisca fazê-la perder a face. O que dá a preeminência à entrevistada que faz uso de uma retórica sofisticada. Há também ironia nesse enunciado que marca a disparidade entre o termo escolhido e a realidade. A ironia pode veicular sentimentos de indignação ou de menosprezo (GRICE, 1989 [1978], p. 54), é suscetível de "legitimar" os dizeres do locutor. Dessa forma, Bettencourt legitima o fato de ter contas no exterior e se mostra intelectualmente forte com relação à reprovação que the é feita. Ao mesmo tempo, o fato de ser a acionária majoritária desse império, que não é uma loja, reforça sua imagem de mulher de negócios poderosa.

\section{Conclusão}

Do ponto de vista teórico, é impossível analisar o processo de restauração da imagem sem levar em consideração a dinâmica entre as duas interlocutoras. Assim, as estratégias de restauração da imagem conhecidas na literatura científica só se desvelam a partir de um estudo minucioso da interação.

Nós constatamos a partir dessa microanálise que a jornalista atenua consideravelmente as ameaças à face da bilionária, procurando ao mesmo tempo responder às exigências da profissão (KOREN, 1996, p. 22). Embora ela anuncie na introdução um tratamento particular em razão da surdez da bilionária, não é realmente em relação a essa enfermidade que a entrevistadora modula sua 
EID\&A - Revista Eletrônica de Estudos Integrados em Discurso e Argumentação, Ilhéus, n. esp. ADARR, mai.2016.

enunciação. De fato, essas trocas verbais parecem confirmar, senão reforçar, o estatuto da classe dominante. A importância que a jornalista confere à imagem da grande dama dá mostras da legitimidade desta na sociedade francesa. Essa interação exprime as leis do grupo, aqui a sociedade francesa, e a definição da situação, que "determinam quantos sentimentos devemos ter pela fachada [face] e como esses sentimentos devem ser distribuídos pelas fachadas [faces] envolvidas ${ }^{16}$ “ (GOFFMAN, 2012 [1967], p. 14). Essa atitude atenuante oferece à bilionária uma posição confortável que facilita sua iniciativa de restauração da imagem. Quando ela detecta um desafio, ela procede imediatamente a estratégias de reparação da imagem. Ora ela ataca sua adversária na interação (ironia, insulto), ora ela usa da negação, da minimização do ato, ou ainda pelo reforço das benfeitorias da empresa que ela possui, apagando-se por trás dela.

É preferencialmente o ethos mostrado (MAINGUENEAU, 1996, p. 40) de uma mulher forte intelectualmente que ela constrói nessa interação, retrabalhando seu ethos prévio. Esse procedimento pôde ser situado a partir de indícios discursivos, mais do que segundo as estratégias de restauração da imagem. Trata-se, para ela, de focalizar a atenção em um procedimento fundado sobre a dignidade da pessoa (que entende mostrar que ela está em plena posse de suas capacidades), desviando, assim, de um procedimetno menos digno - a restauração da imagem manchada por causa de um caso de corrupção.

A mulher de negócios mobiliza, portanto, técnicas de retrabalho do ethos e de restauração da imagem mesmo quando ela demonstra uma indiferença em relação a sua imagem pública. Essa aparência de indiferença pode em si, entretanto, constituir uma medida de eficácia. Mencionar o procedimento de reconstrução seria estragar a iniciativa. Ora, a recusa de retrabalhar sua imagem, e a da marca da empresa, por ricochete, pode justamente dar a impresão de que a L'Oréal é tão sólida que ela não pode depender da imagem pública de sua acionária principal.

\section{Referências}

AMOSSY, R; HERSCHBERG, P. A. Stéréotypes et clichés. Langue, Discours, Société. Paris: Nathan, 1997.

AMOSSY, R. L'argumentation dans le discours. Discours politique, littérature d'idées, fiction. Paris : Nathan, 2000.

16 No original: "determine how much feeling one is to have for face and how this feeling is to be distributed among-the-faces-involved." 
EID\&A - Revista Eletrônica de Estudos Integrados em Discurso e Argumentação, Ilhéus, n. esp. ADARR, mai.2016.

France, 2010.

. La présentation de soi. Ethos et identité verbale. Press Universitaire de . L’apologie de la polémique. Paris: PUF, 2014.

ARFI, F. ; LHOMME, F. (avec la rédaction de Mediapart). L'affaire Bettencourt, un scandale d'état. Don Quichotte, 2010.

AUSTIN, J.L. A plea for excuses. Philosophical Papers. Oxford: Clarendon Press, p.123152, 1961.

BENOîT, W. L. Accounts, excuses and apologies: A theory of image restoration strategies. Albany, NY: State University of NY Press, 1995.

BLUM-KULKA, S. The dynamics of political interviews. Text, vol. 3, 2, p.131-153, 1983.

BROWN, P.; LEVINSON, S. C. Politeness. Some Universals in Language Usage. Cambridge: Cambridge University Press, 1987 [1978].

BURKE, K. A rhetoric of motives. Berkeley: University of California, 1969.

CHARAUDEAU. P; MAINGUENEAU, D. [Eds.]. Dictionnaire de l'analyse du discours. Paris: Seuil, 2002.

CLAYMAN, S.; HERITAGE, J. The News Interview. Journalists and Public Figures in the Air. Cambridge: Cambridge University Press, 2002.

COULOMB-GULLY, M. Rhétorique télévisuelle et incarnation politique. Eléments de réflexion. Réseaux, vol.17, n. 94, p.195-213, 1999.

Dictionnaire de Français Larousse. Disponível em: http://www.larousse.fr/dictionnaires/francais/man\%C5\%93uvre/49208?q=manoeuvre\# 49115. Acesso: 10 nov. 2015.

DUCROT, O. Dire et ne pas dire: principes de sémantique linguistique. 3. ed. Paris: Hermann, 1991.

FLOTTUM, K; JONASSON, K; NORÉN, C. On: pronom à facettes. Bruxelles : de Boeck, 2007.

GOFFMAN, E. Interaction Ritual. New York: Anchor Books, 1967. Tradução em português: GOFFMAN, E. Ritual de Interação. 2. edição. Tradução de Fábio Rodrigues Ribeiro da Silva. São Paulo: Editora Vozes, 2012.

GRICE, P. Studies in the Way of Words. London: Harvard University Press, 1989 [1978].

JUCKER, A. H. News Interviews: A pragmalinguistic Analysis. Amsterdam/Philadelphia: John Benjamins Publishing Company, 1986. 
EID\&A - Revista Eletrônica de Estudos Integrados em Discurso e Argumentação, Ilhéus, n. esp. ADARR, mai.2016.

KANTOROWICZ, E. H. The King's two bodies: A study in Medieval Political Theology. Princeton University Press, 1997.

KERBRAT-ORECCHIONI, C. L'énonciation de la subjectivité dans le langage. Paris: Armand Colin, 1980.

. Les interactions verbales. Tome 1: Approche interactionnelle et structure des conversations. Paris : Armand Colin, 2010 [1990].

KOREN, R. Les enjeux éthiques de l'écriture de presse ou la mise en mots du terrorisme. Paris: L'Harmattan, 1996.

LAVOV, W.; FANSHEL, D. Therapeutic discourse. London: Academic Press, 1977.

MAINGUENEAU, D. Les termes clés de l'analyse du discours. Paris: Seuil, coll. «Mémo», 1996.

MCLAUGHLIN, M. L.; CODY, M. J.; ROSENSTEIN, N. E. Account sequences in conversations between strangers. Communication Monographs, vol. 50, n. 2, p. 102$125,1983$.

OWSLEY, H. H.; MYERS-SCOTTON, C. The conversational expression of power by television interviewers. The Journal of Social psychology, vol. 123, n. 2, p. 261-271, 1984.

PERELMAN, C.; OLBRECHTS-TYTECA, L. Traité de l'argumentation. La nouvelle rhétorique. Bruxelles : Editions de l'Université de Bruxelles, 2008 [1958].

SCHEGLOFF, E. A.; JEFFERSON, G.; SACKS, H. The Preference for Self-correction in the Organization of Repair in Conversation. Linguistic Society of America, vol 53, n. 2, p. 361-382, 1977.

WARE, B. L.; LINKUGEL, W. A. They spoke in defense of themselves: on the generic critism of apologia. Quaterly Journal of Speech, 59, p. 273-83, 1973.

WEIZMAN, E. Positioning in Media Dialogue. Amsterdam/Philadelphia: John Benjamins Publishing Company, 2008.

- Positionnement par le défi: les négociations des rôles dans l'interview télévisée. Questions de communication, n. 2, p.135-150, 2006.

Como citar:

SADOUN-KERBER, Keren. A restauração da imagem entre análise do discurso e ciências da comunicação: o caso da entrevista televisionada de Liliane Bettencourt. Trad. Luís Fernando Bulhões Figueira. EID\&A - Revista Eletrônica de Estudos Integrados em Discurso e Argumentação, Ilhéus, n. esp. ADARR, p. 93-120, mai.2016. 